\title{
Large-Area Dense Plasmonic Nanoarrays for Surface Enhanced Raman Applications
}

V. Liberman, T. M. Bloomstein, M. Rothschild

Lincoln Laboratory, Massachusetts Institute of Technology

Lexington, MA 02420

C. Yilmaz, S. Somu, Y. Echegoyen, A. Busnaina

NSF Nanoscale Science and Engineering Center for High-Rate

Nanomanufacturing, Northeastern University

Boston, MA 02115

June 23, 2010 


\section{Outline}

- Introduction to SERS

- Interference lithography as array fabrication platform

- Scheme I: Convective assembly of plasmonic structures

Fabrication, Characterization, E-M modeling

- Scheme II: Direct metal deposition of plasmonic structures

Raman uniformity mapping

- Summary 


\section{Surface Enhanced Raman Spectroscopy}

- SERS discovered over 30 years ago

- Jeanmaire and Van Duyne, 1977

- Albrecht and Creighton, 1977

- Orders of magnitude increase in Raman cross-section in the vicinity of plasmonic surfaces

- Unenhanced: $10^{-29} \mathrm{~cm}^{2}$

- Enhancements of $10^{10}$ makes it as bright as fluorescence!

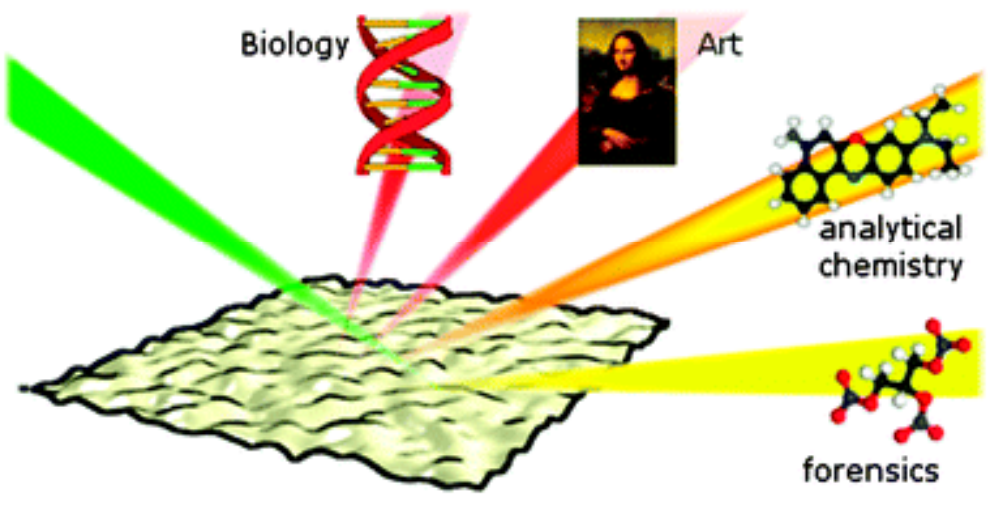

Quo vadis surface-enhanced Raman scattering?

Phys. Chem. Chem. Phys., 2009, 11, 7348

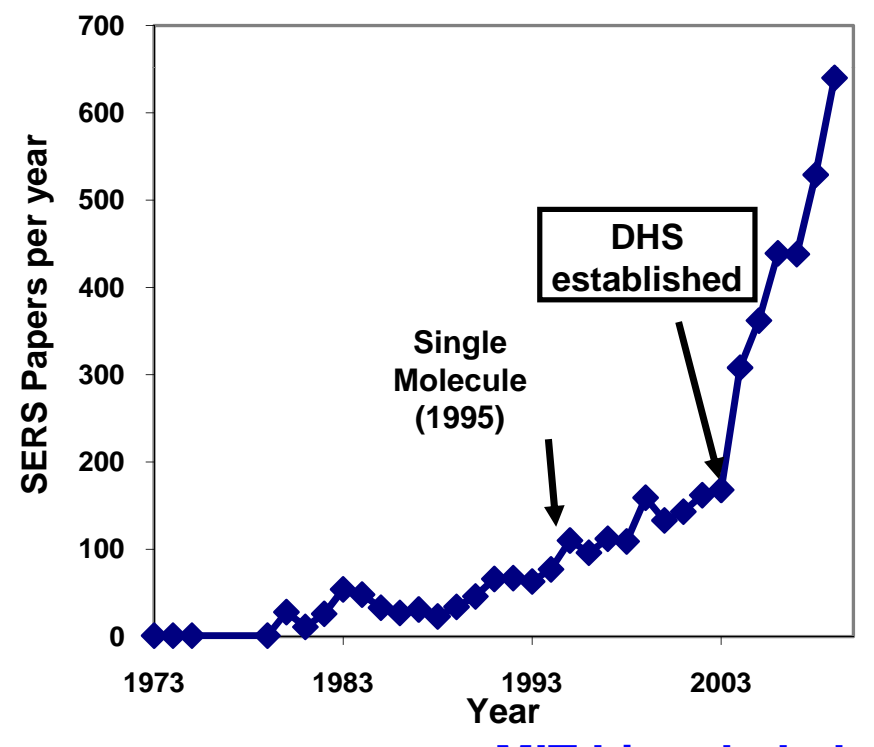




\section{So, Where are We Now?}

- SERS discovered over 30 years ago

- Orders of magnitude increase in Raman cross-section in the vicinity of plasmonic surfaces

- Dominated by electromagnetic near-field resonant enhancement

- Single molecule sensing at "hot spots" or "hot junctions"

- Yet, significant challenges remain before wide implementation

- Practical implementation requires engineering of highdensity "hot-spot substrates" with $\mathrm{nm}$ precision over large areas on the order of $\mathrm{cm}^{2}$

Low cost and high throughput

Reproducibility and signal uniformity

- Formidable nanofabrication challenge due to "nm-cm" length scale mismatch 


\section{Importance of Hot Spots}

- Rapid increase of E-field enhancement for gap sizes under $10 \mathrm{~nm}$

- Since enhancement is localized, "nanogap" density must be maximized for optimum sensitivity

\section{J. Phvs. Chem. B 2003, 107, 7607-7617}

Local Electric Field and Scattering Cross Section of Ag Nanoparticles under Surface Plasmon Resonance by Finite Difference Time Domain Method

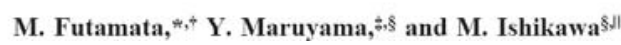
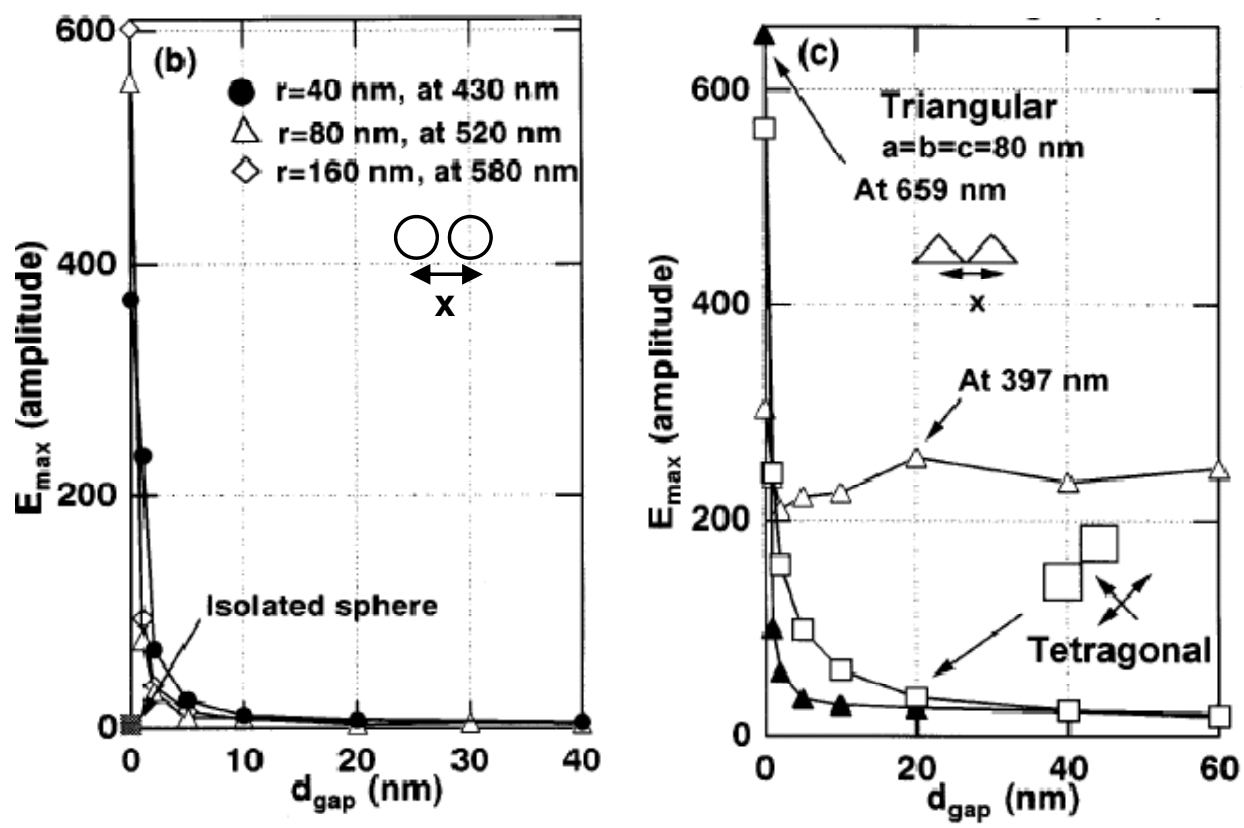


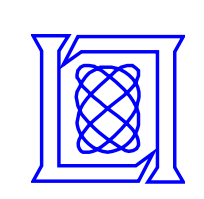

\section{Methods of Forming High Densities of Hot Spots}

\begin{tabular}{|c|c|c|c|}
\hline Approach & Authors & Pros & Cons \\
\hline $\begin{array}{c}\text { Self-Assembly } \\
\vdots \because \because \because \\
\vdots \because \because\end{array}$ & $\begin{array}{l}\text { Freeman, et al. } \\
\text { Science (1995) } \\
267(5204): 1629- \\
32\end{array}$ & -Cheap and easy & $\begin{array}{l}\text {-Uniform spacing } \\
\text { and gap control are } \\
\text { difficult to achieve }\end{array}$ \\
\hline $\begin{array}{l}\text { Ag-over } \\
\text { nanosphere } \\
\text { lithography }\end{array}$ & $\begin{array}{l}\text { The Van Duyne } \\
\text { group, } \\
\text { Northwestern } \\
\text { University }\end{array}$ & $\begin{array}{l}\text {-Large area coverage } \\
\text {-Triangular shapes } \\
\text {-Cheap } \\
->10^{7} \text { EF reported }\end{array}$ & $\begin{array}{l}\text { - Small gap spacing } \\
\text { difficult to achieve }\end{array}$ \\
\hline $\begin{array}{l}\text { AAO } \\
\text { template- } \\
\text { assisted }\end{array}$ & $\begin{array}{l}\text { Mu et al. (2009) } \\
\text { Nanotechnology } \\
\text { 21: } 015604 .\end{array}$ & $\begin{array}{l}\text {-Large area coverage } \\
\text {-Gap spacing control } \\
\text {-Relatively cheap } \\
-10^{7} \text { EF reported }\end{array}$ & $\begin{array}{l}\text {-Limited shape } \\
\text { control } \\
\text {-Uniformity issues }\end{array}$ \\
\hline 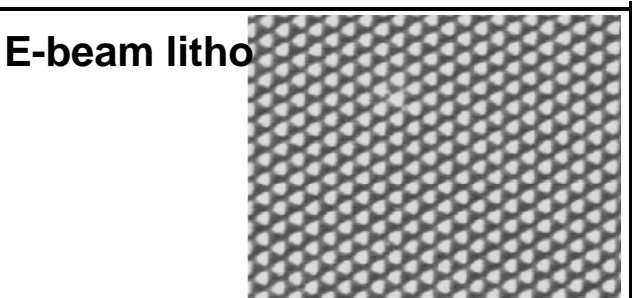 & $\begin{array}{l}\text { Gunnarsson et al. } \\
\text { (2001) Applied } \\
\text { Physics Letters } \\
78(6): 802-4 .\end{array}$ & $\begin{array}{l}\text {-Shape control } \\
\text {-Gap spacing control } \\
\text {-Very high EF possible }\end{array}$ & $\begin{array}{l}\text {-Expensive } \\
\text {-No scale up } \\
\text { potential }\end{array}$ \\
\hline
\end{tabular}




\section{Our Approach to Scalable Substrates}

- Platform: Lithographically defined templates

- 157-nm interference lithography

- Crossed exposures allow dense pattering of holes or posts

- Two metal deposition schemes

1. Convective assembly of individual nanoparticles into templates

Decouple nanoshape fabrication from placement

2. Direct evaporation of plasmonic metal through template openings

- Structure design/optimization with electromagnetic simulations 


\section{Interference Lithography for Template Patterning}

- Unique interference lithography system operating at $157 \mathrm{~nm}$

- Forms high-resolution periodic arrays with high throughput (compared to e-beam)

- Half-pitch from 45 to $22 \mathrm{~nm} \quad \longrightarrow \quad$ highest optical resolution

- The short wavelength also enables novel photochemistry

- Direct patterning of PMMA, $\mathrm{SiO}_{2}$, etc.

- Chemical surface modification

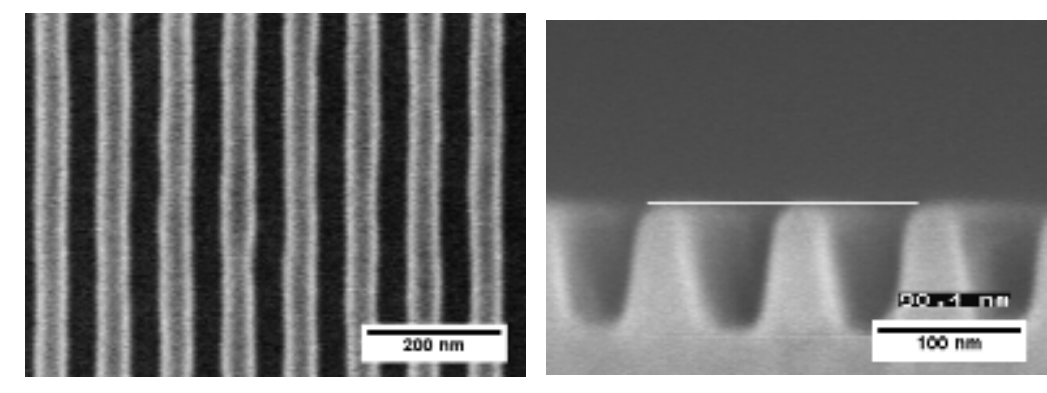

45-nm lines etched to $90-\mathrm{nm}$ depth

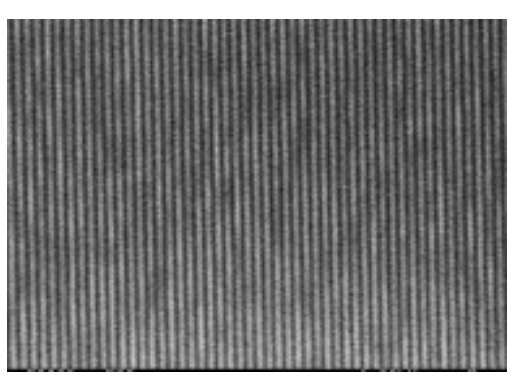

22-nm lines

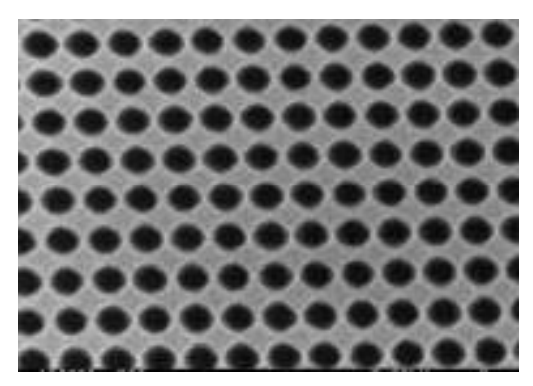

75-nm circles cut into $\mathrm{SiO}_{2}$

These capabilities enable new applications

- Lithography

- Nanophotonics

- Nanofluidics

- Biotechnology 


\section{Template Fabrication for Nanoassembly}

- Two crossed exposures in PMMA

- $1.5 \mathrm{~mJ} / \mathrm{cm}^{2}$ dose for each exposure

- $10 \mathrm{sec}$ for each exposure

- Exposure followed by 30 sec MIBK/IPA develop

- Only a single litho step - simple processing!

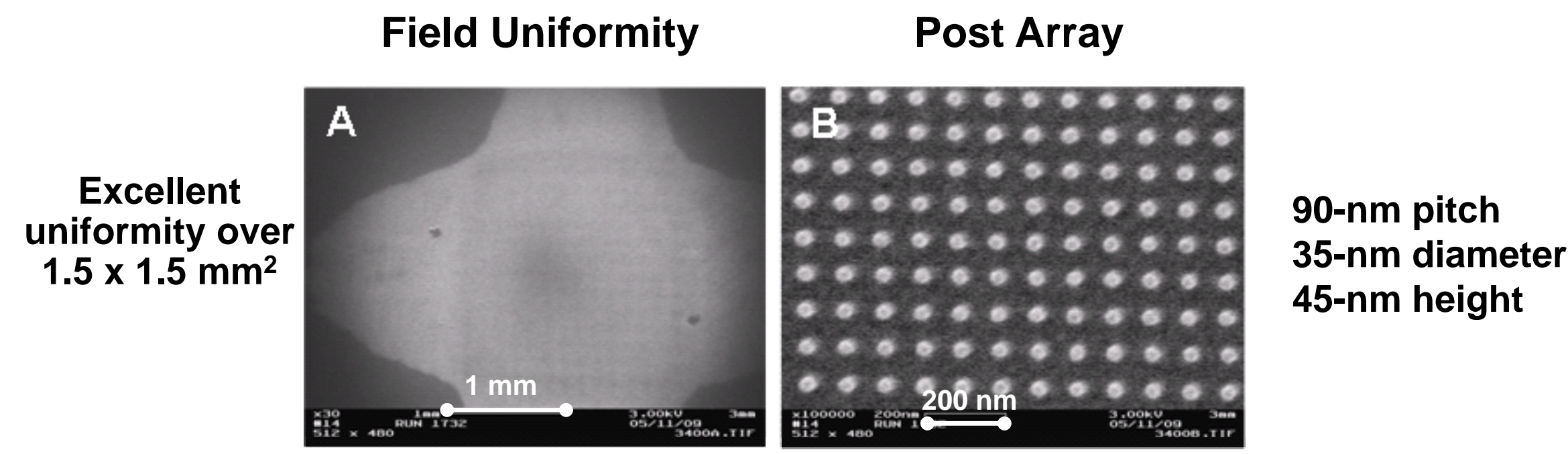




\section{Convective Assembly from Colloidal Suspension}

- Particle transport towards the surface through convective flow of the colloidal suspension towards the liquid meniscus

- Assembly assisted by

- Surface energy difference between hydrophilic gold and hydrophobic PMMA

- Clamping action of the PMMA posts

- Capillary forces of the nanocrevices

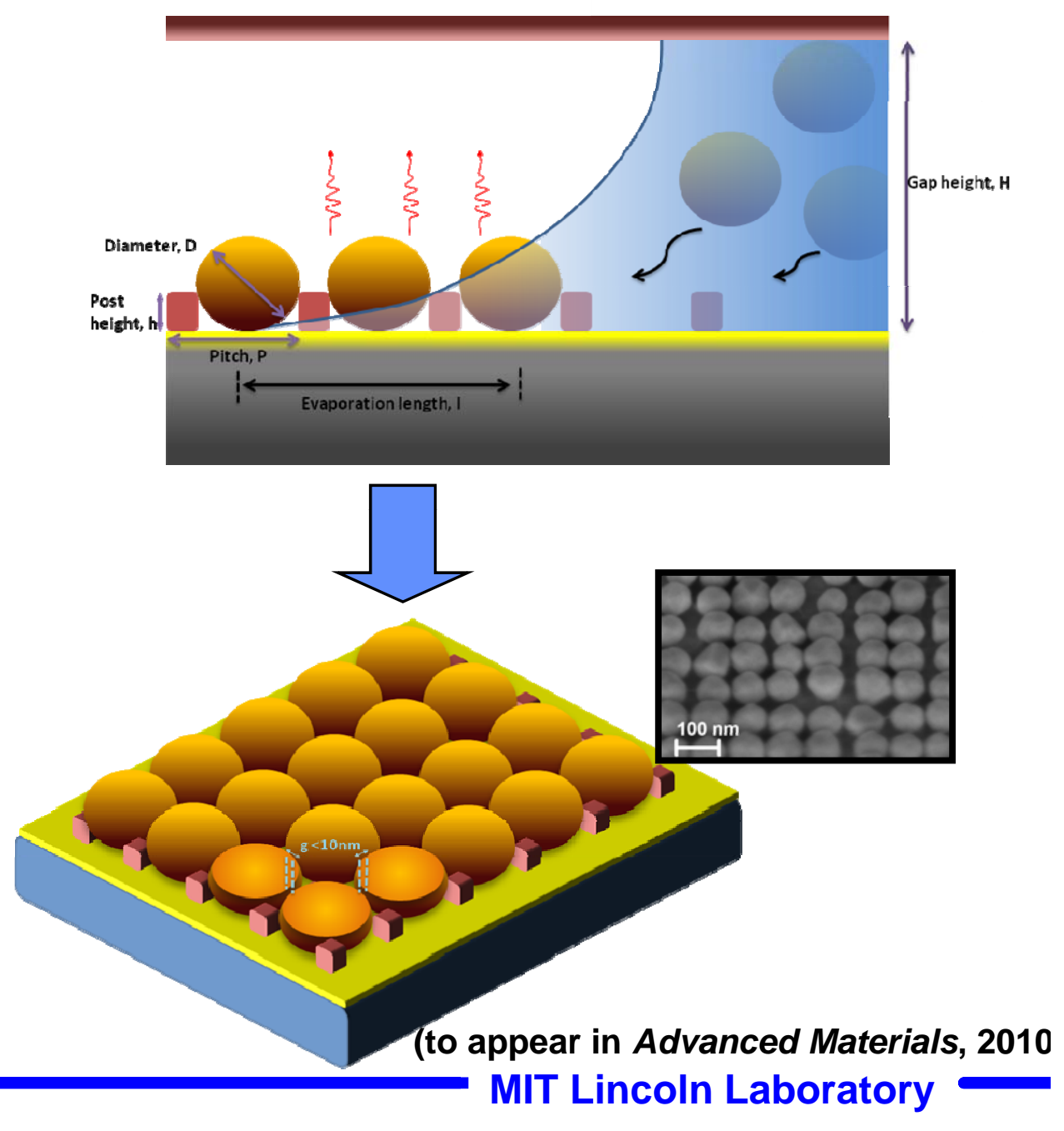




\section{Assembly Without Nanotemplate}
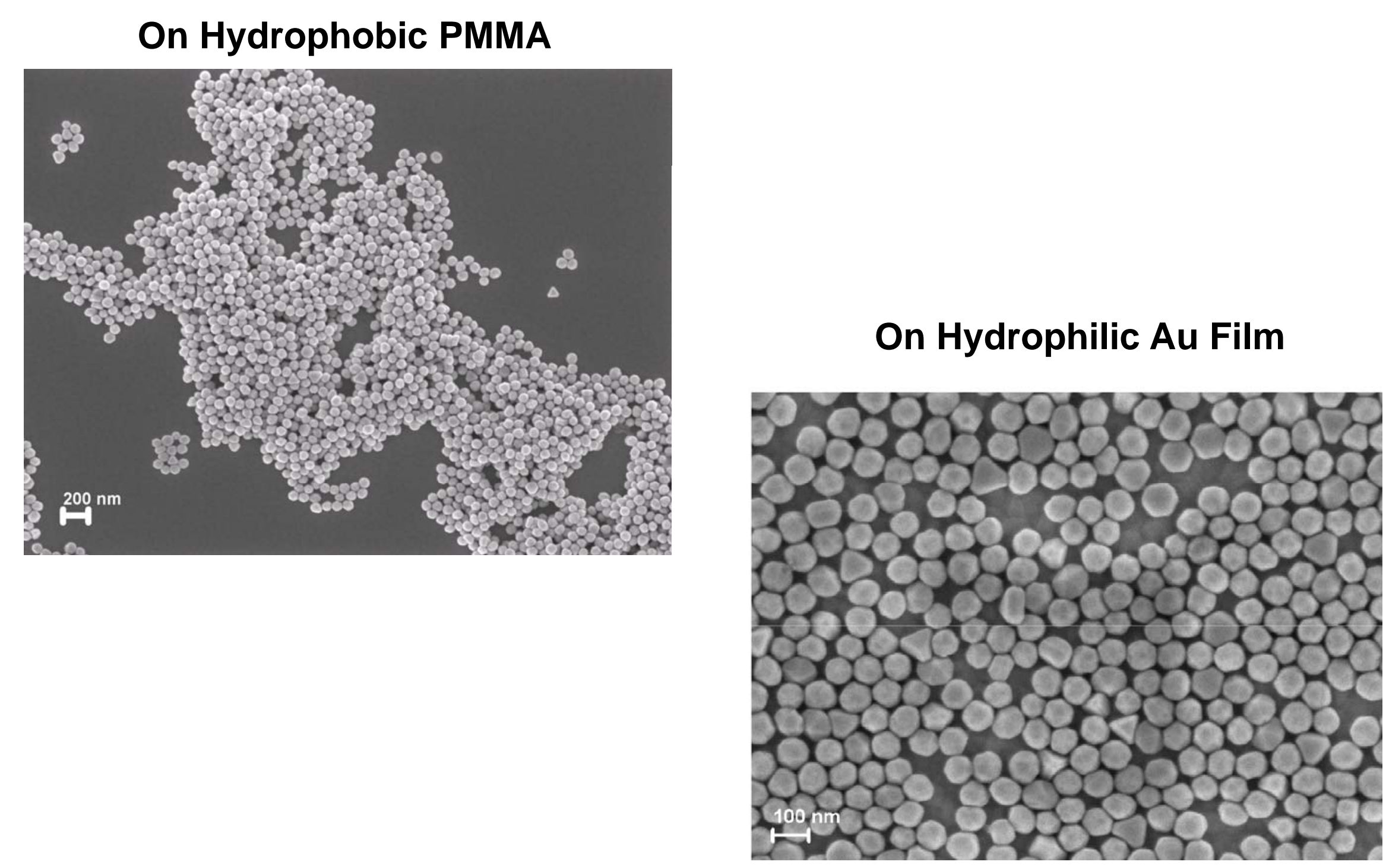


\section{Convective Assembly Onto Templated Surface}

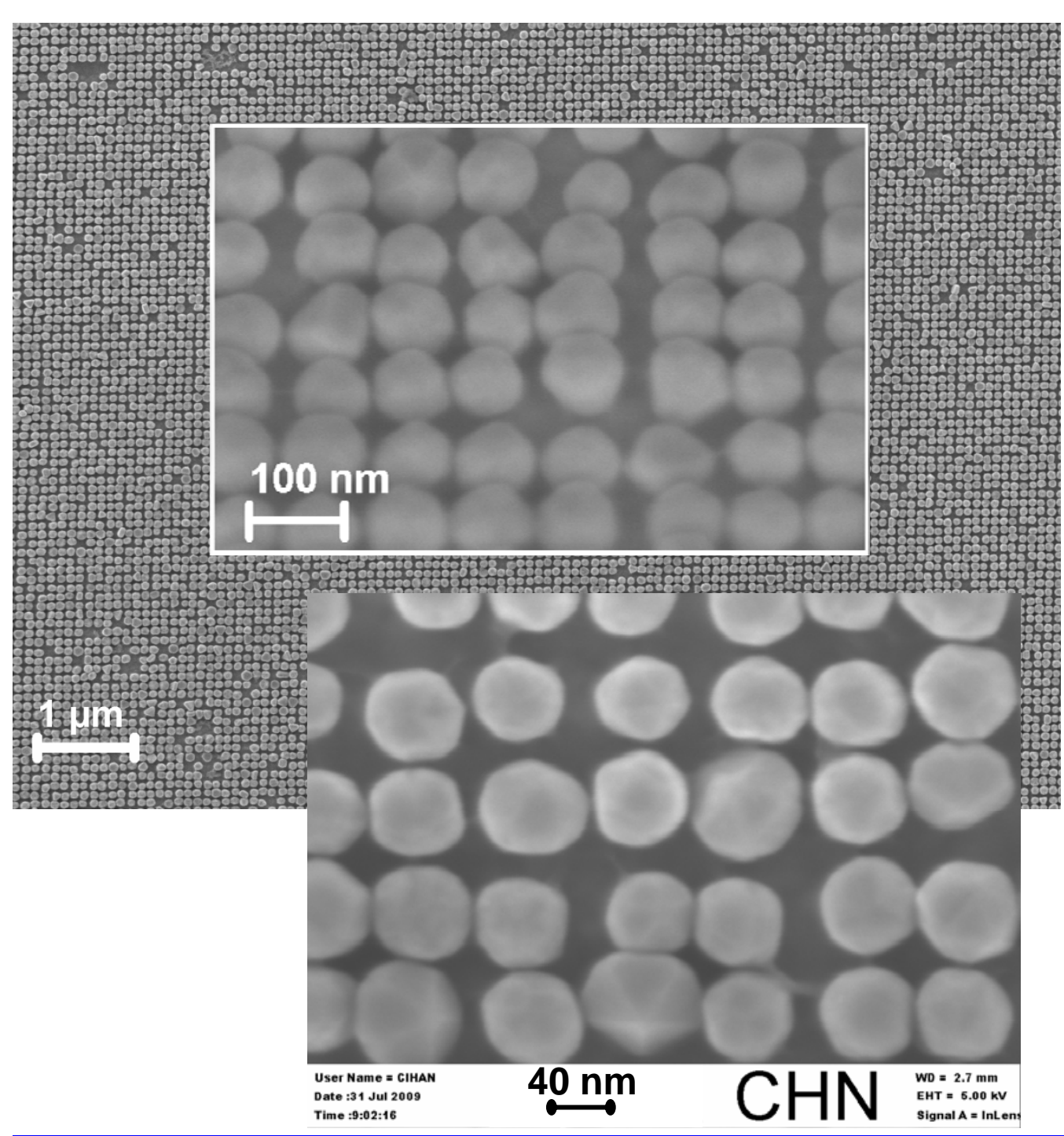

- Contiguous templating over $15 \times 15 \mu \mathrm{m}^{2}$ areas

- Multiple assembled areas per lithographic field

- Gap size variation dominated by particle nonuniformity

$-80 \mathrm{~nm} \pm 8 \mathrm{~nm}$ in solution, as quoted by supplier

- Gap size estimated at $10 \pm 5 \mathrm{~nm}, 1 \sigma$

- Further reduction in gap size and variation can be achieved 


\section{Measuring Plasmonic Resonances}

- Darkfield Rayleigh backscatter measurements

- Darkfield mode suppresses Au reflection background

- Microreflectance for spatial resolution

- Resonance peak strongly red-shifted cf. solution resonance

- From $550 \mathrm{~nm}$ for particles in solution to $\approx 750 \mathrm{~nm}$ for nanoassembly

- Nearest-neighbor interactions

- Good overlap of resonance with both Raman excitation and Stokes scattered photons

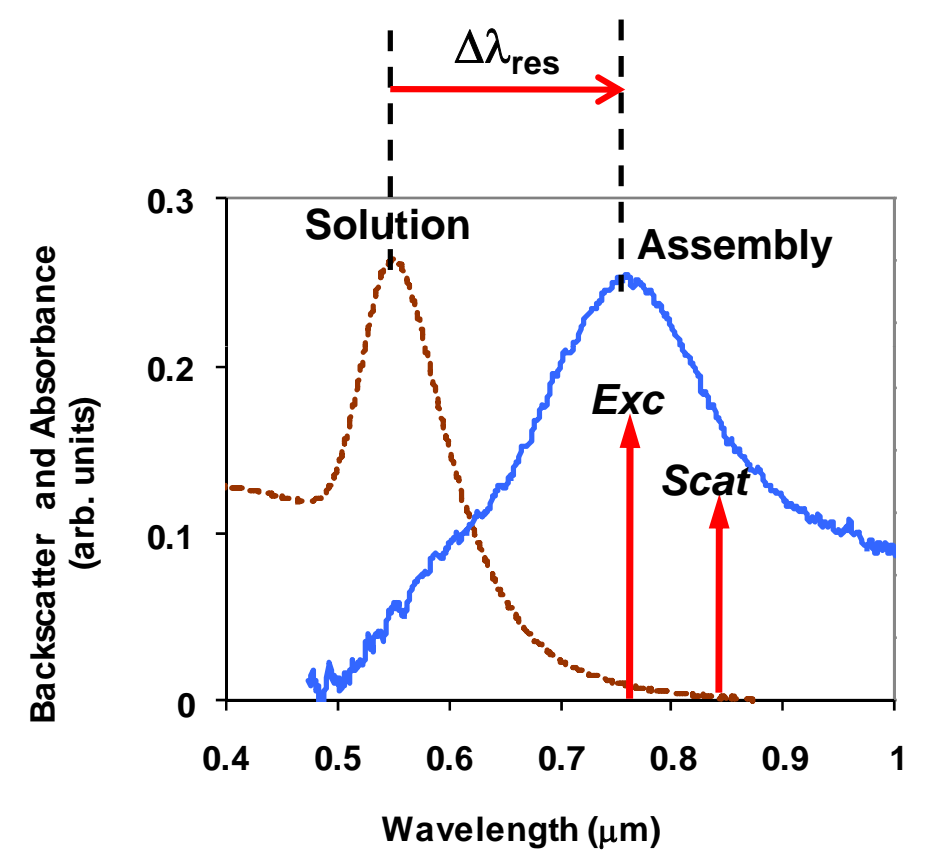




\section{Modeling E-field Enhancement with FDTD}

- Good agreement in wavelength peak position with measured backscatter

- Hot spots spatially localized

- $\quad 2 \%$ area contributes to $>95 \%$ of SERS signal

- $7 \times 7 \mathrm{~nm}^{2}$ area of adsorbates per "hot spot"
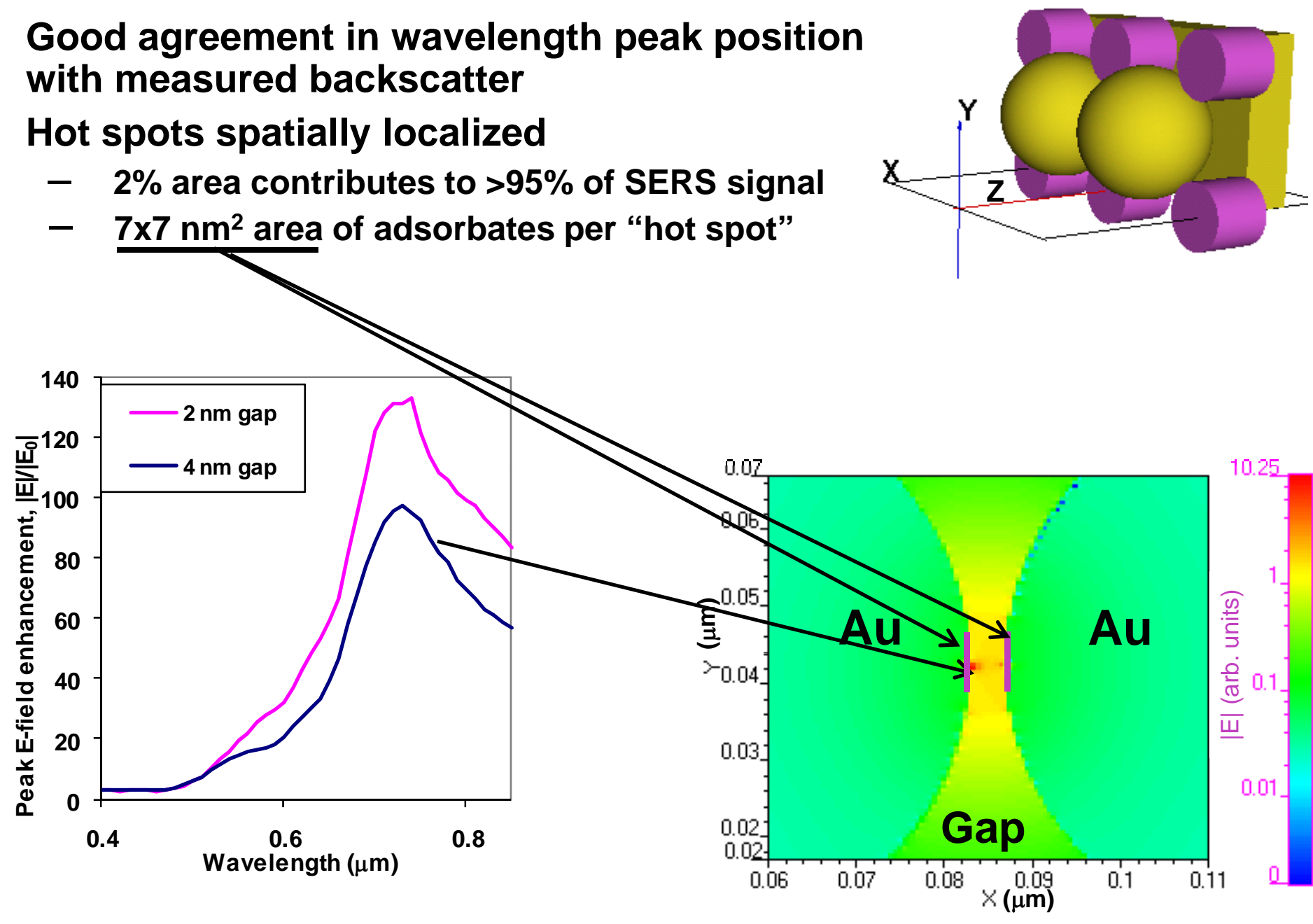


\section{SERS Spectra of Benzenethiol From Nanoassembled Regions}

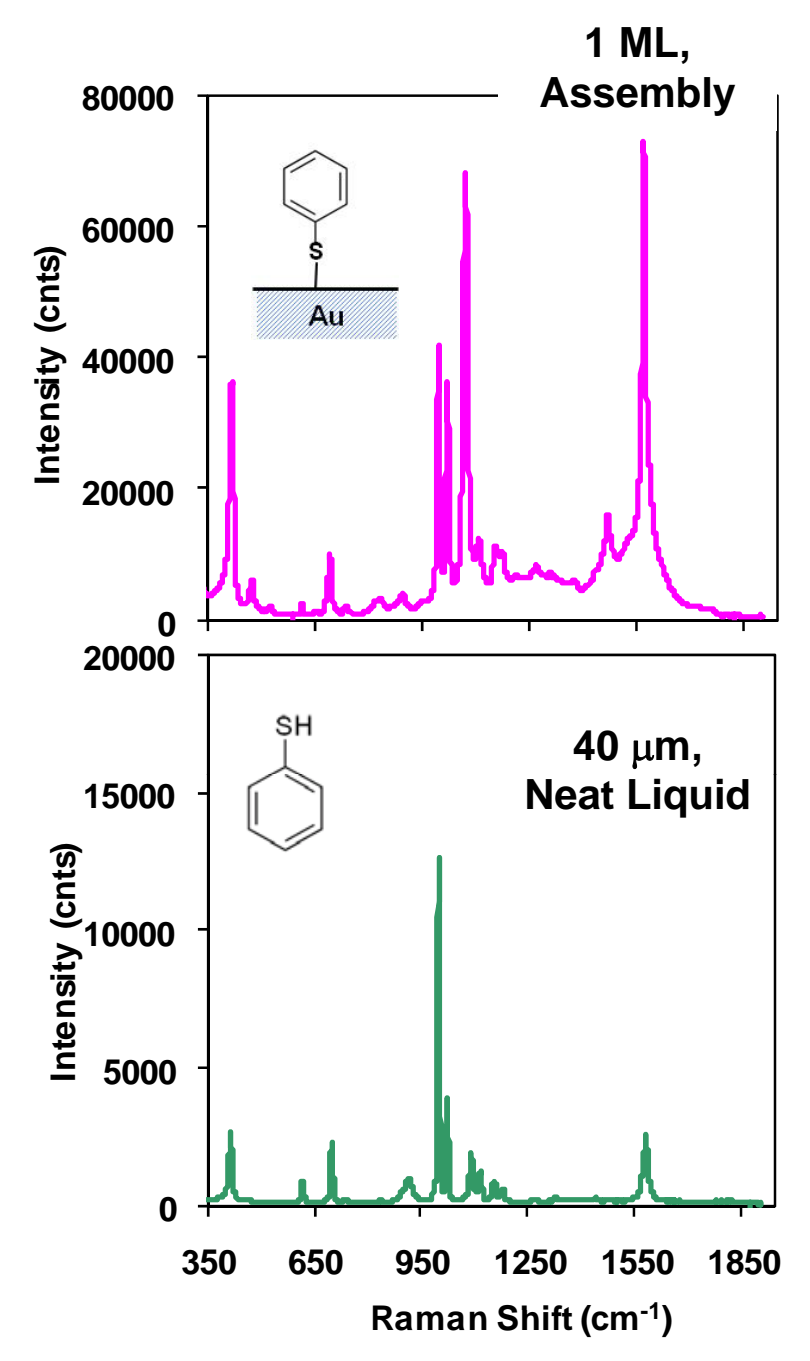

Different Assembly Regions (15x15 $\left.\mu \mathrm{m}^{2}\right)$ Within One Field $\left(1.5 \times 1.5 \mathrm{~mm}^{2}\right)$

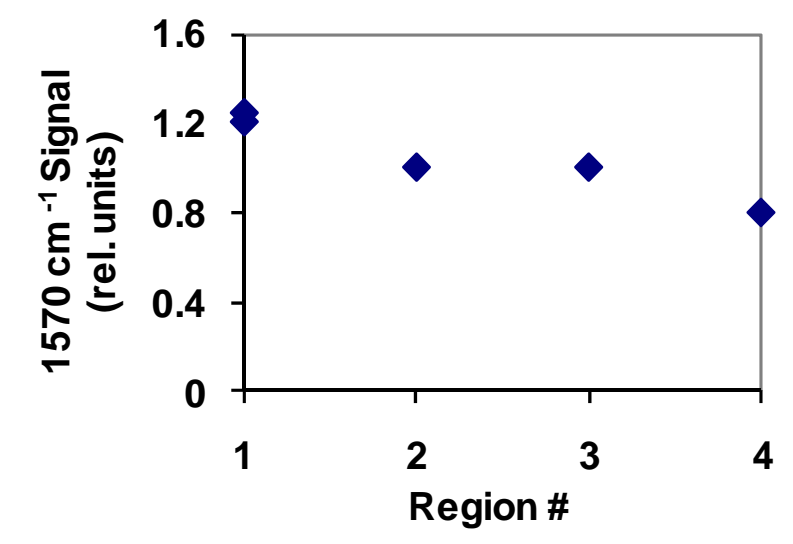

- Average Enhancement Factor $5 \times 10^{6}$

- Over $6 \mu \mathrm{m}$ measurement spot

- Compares well with other published work for nanoarrays

- Using the same conservative definition of EF

- $\pm 20 \%$ repeatability over different assembly regions 


\section{Possible Extension of Nanoassembly - Novel Nanoshapes}

- Surface field enhancement depends strongly on nanoparticle shape

- Sharp corners and tips help to focus fields to form hot spots

Increasing Surface Field Enhancement from Simulations

$\left|E_{\text {max }}\right| /\left|E_{\text {inc }}\right|$

Previous work

Yang, et al.

J. Phys. Chem. C, Vol. 111, No. 26, 2007

25

70

140
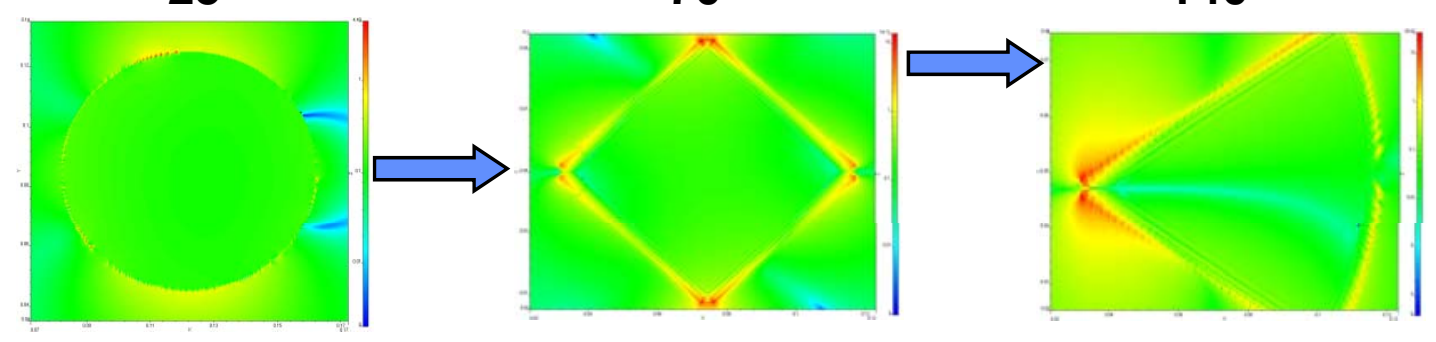

- Based on previous work, custom synthesis of nonspherical particles in solution is feasible
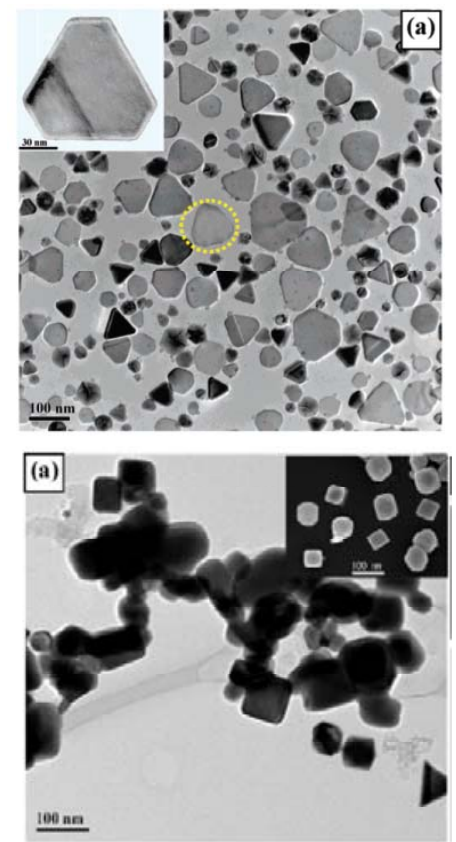


\section{Direct Nanocone Patterning of SERS Structures}

- As an alternative to templated nanoassembly, we fabricated metal structures using direct metal deposition

- Interference lithography used to pattern openings in a dielectric stack

- Offers flexibility of different metal depositions

- Not only Au but also Ag

- No lift-off: metal surface is not exposed to chemicals

- Potential for formation of 3-dimensional structures

- Cone tips inside cavities 


\section{Nanocone Array Fabrication}
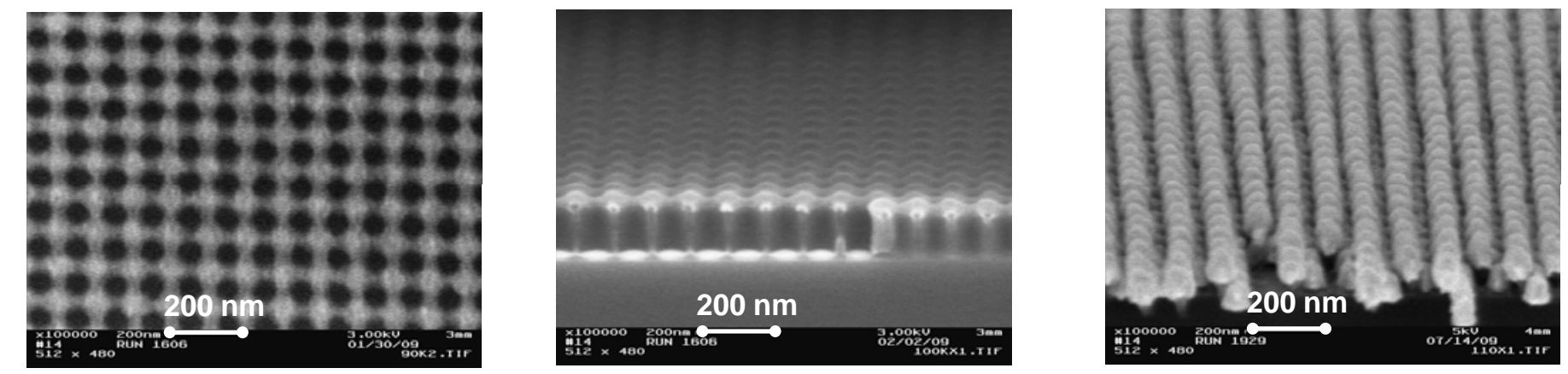

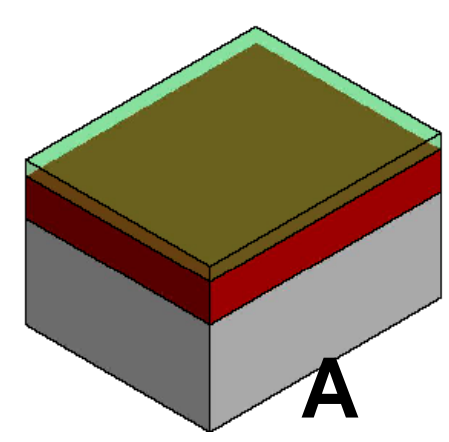

Stack deposition

- $55 \mathrm{~nm}$ SOG/80 nm AR3/Si Wafer

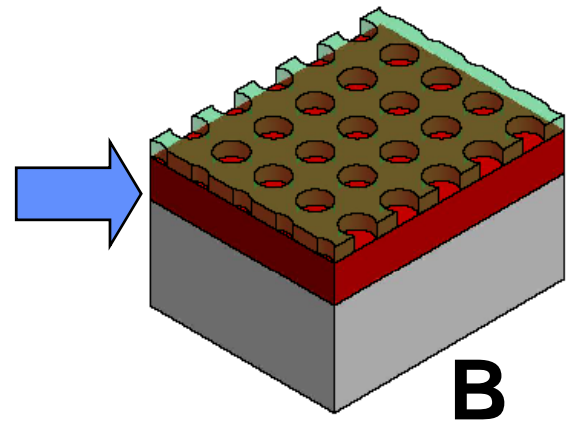

Litho exposure/develop

- Two cross exposures

- TMAH development

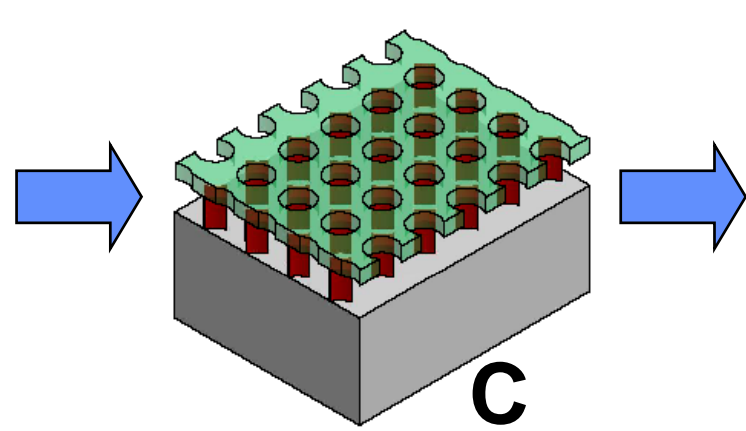

RIE $\mathrm{O}_{2}$ etch

- Through AR3

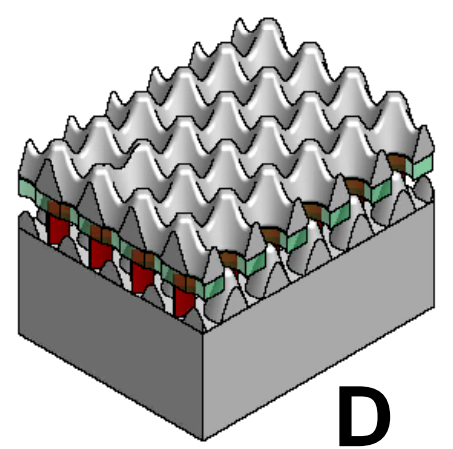

Ag/Au deposition - E-beam assisted 


\section{SEMs of Final 3-D Nanostructures}
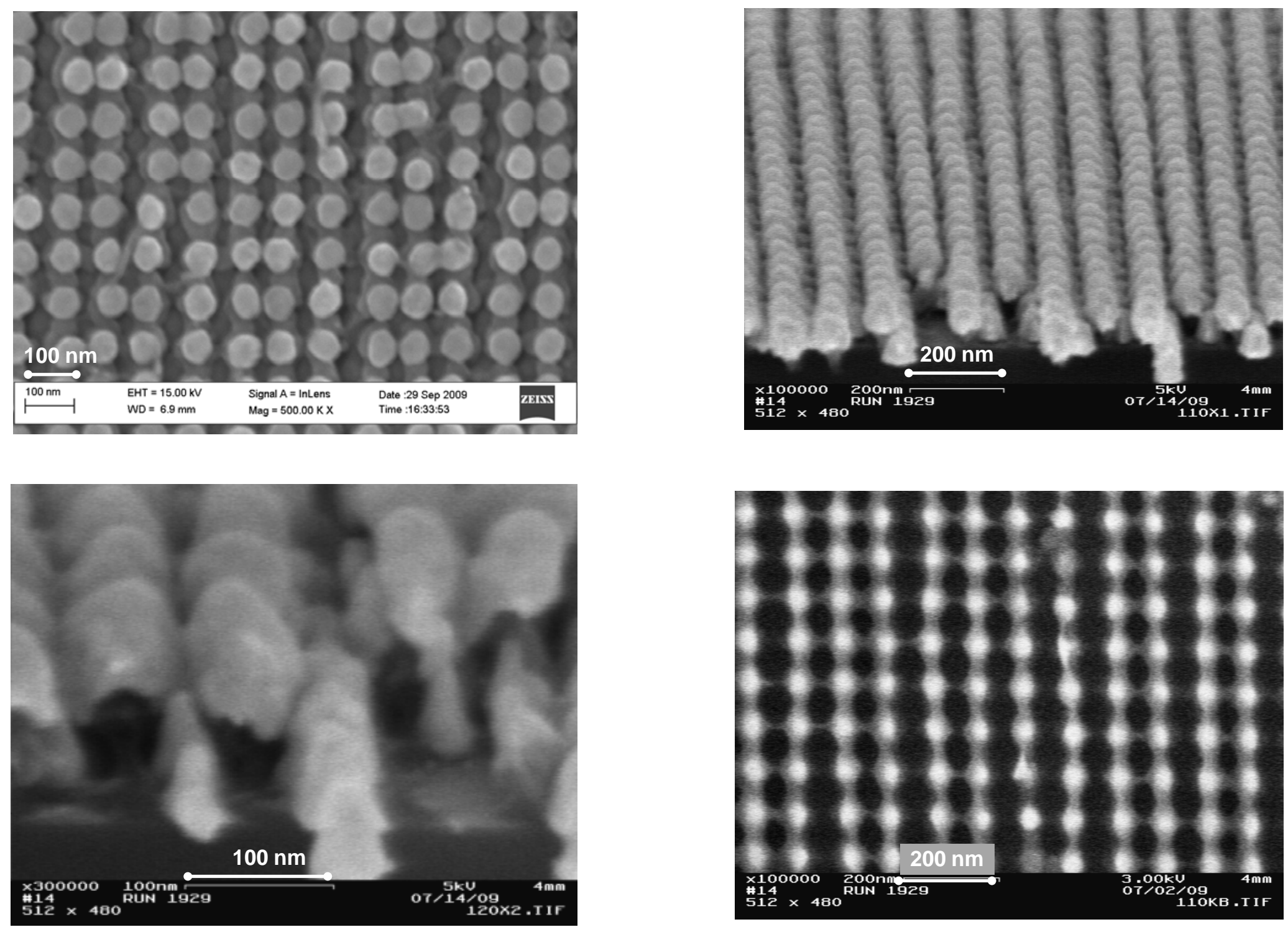


\section{SERS Uniformity Mapping}

- Benzenethiol-treated Ag

- 532-nm excitation

- $30 \mu \mathrm{m}$ measurement spot

- Good signal uniformity over the full patterned field

- $\sim 1.5 \times 1.5 \mathrm{~mm}^{2}$ area

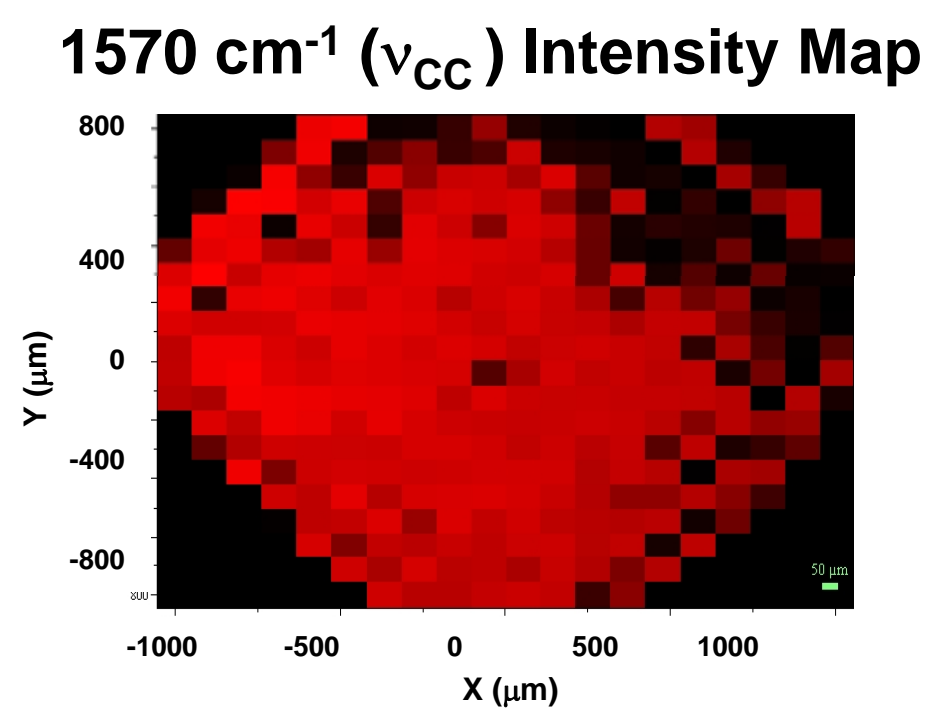


 \\ Summary of Average SERS Enhancement Factors}

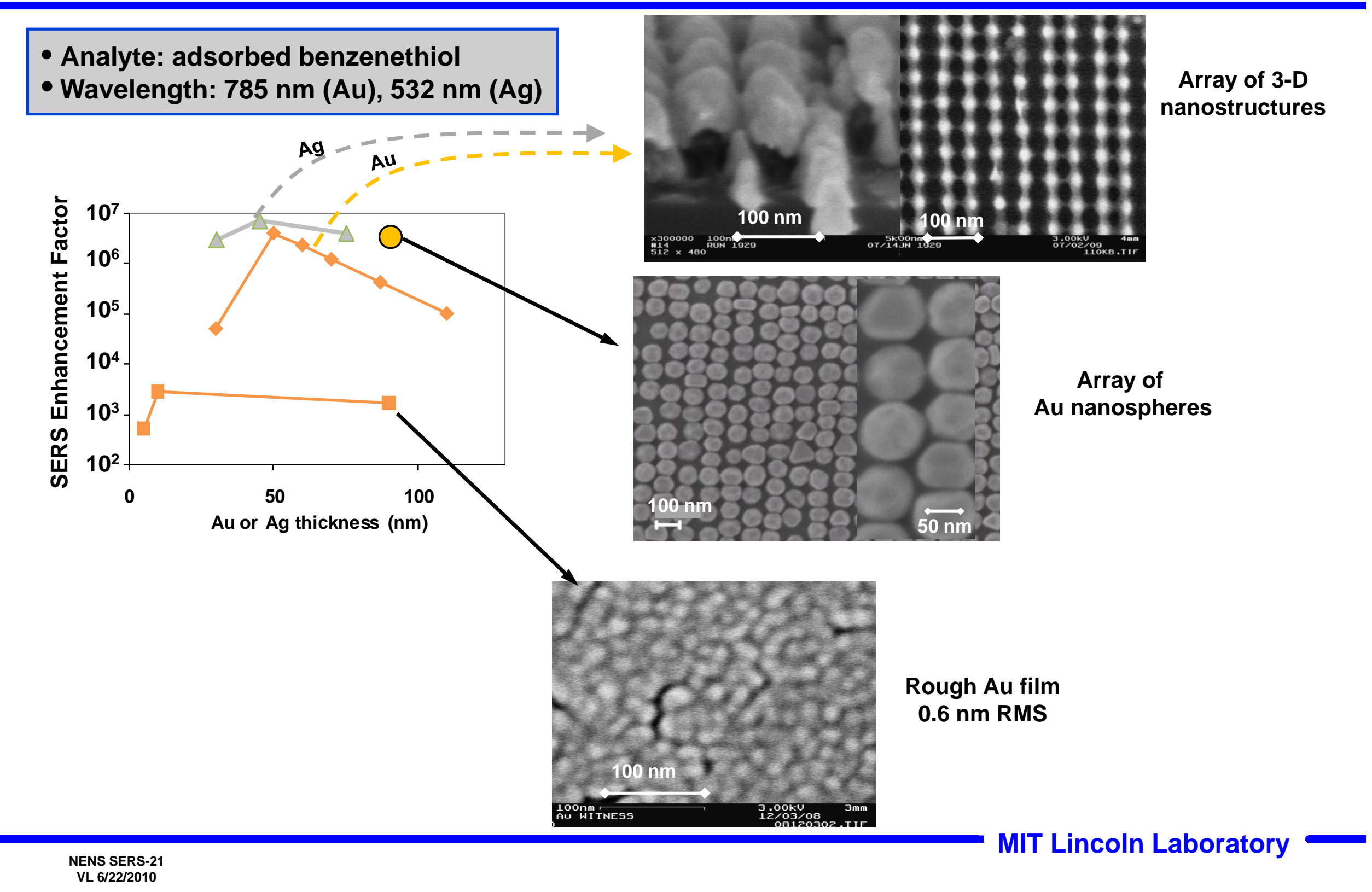




\section{Summary}

- Developed two methods of fabricating high-density of SERS "hot spots"

- Nanoassembly-assisted fabrication technique decouples shape/material optimization from placement

- Direct pattern/deposition techniques offers the possibility of tailored 3-D structures for optimum field enhancement

- Techniques are scalable to wafer-size area with high throughput

- Multiple $\mathrm{mm}^{2}$ areas with step-and-repeat

- Demonstrated average enhancement factors of $>5 \times 10^{6}$ over $\mathrm{mm}^{2}$ areas

- Comparable to state-of-the art over large areas

- Further optimization should improve performance 


\section{Acknowledgments}

- The Raman measurements performed in this work made use of the MRSEC Shared Experimental Facilities supported by the National Science Foundation under award number DMR-08-19762. The assembly experiments and scanning electron microscopy were conducted at the George J. Kostas Nanoscale Technology and Manufacturing Research Center at Northeastern University.

- The Lincoln Laboratory portion of this work was supported by the Defense Advanced Research Projects Agency under Air Force contract FA8721-05-C-0002. Opinions, interpretations, conclusions, and recommendations are those of the authors, and do not necessarily represent the view of the United States Government.

- The CHN portion of this work was supported by the National Science Foundation Nanoscale Science and Engineering Center (NSEC) for High-Rate Nanomanufacturing (NSF grant - 0425826). 